Décadrages Décadrages

cinéma, à travers champs Cinéma, à travers champs

$7 \mid 2006$

Stephen Dwoskin

\title{
Wer war Kafka ? (Richard Dindo, 2005)
}

\section{Alain Boillat}

\section{(2) OpenEdition}

\section{Journals}

Édition électronique

URL : https://journals.openedition.org/decadrages/490

DOI : $10.4000 /$ decadrages. 490

ISSN : 2297-5977

\section{Éditeur}

Association Décadrages

\section{Édition imprimée}

Date de publication : 10 avril 2006

Pagination : 127-128

ISBN : 978-29700582-3-6

ISSN : 2235-7823

Référence électronique

Alain Boillat, «Wer war Kafka? (Richard Dindo, 2005) », Décadrages [En ligne], 7 | 2006, mis en ligne le 31 janvier 2014, consulté le 03 avril 2022. URL : http://journals.openedition.org/decadrages/490 : DOI : https://doi.org/10.4000/decadrages.490

Ce document a été généré automatiquement le 3 avril 2022.

(B) Décadrages 


\title{
Wer war Kafka? (Richard Dindo, 2005)
}

\author{
Alain Boillat
}

1 A n'en pas douter, ce documentaire donne à la question de son titre une réponse fouillée et sensible qui corrèle la vie de l'écrivain avec la ville natale qu'il n'a presque jamais quittée. Ce parcours à travers les rues de Prague est notamment accompagné de la prose kafkaïenne (les textes biographiques comme le crucial Brief an den Vater) dont Dindo saisit la musicalité par un jeu savant de répétitions, de fragmentations et d'échos qui tissent un réseau complexe de liens avec les images. Le film mêle des vues fixes et animées contemporaines et d'archives, et fait intervenir sous une forme étonnamment incarnée (par des acteurs professionnels devenus personnages, et non pas sur un mode straubien) ceux qui ont connu Kafka (Max Brod, Gustav Janouch et les trois amours de l'écrivain): ces locuteurs apparaissent et disparaissent en fondus avec cette évanescence dont se pare la résurgence du passé. La démarche de " reconstitution » est intéressante, mais ces bustes éclairés en studio et incrustés dans le plan se détachent des images de Prague qui défilent derrière eux avec un effet de silhouette d'une rare laideur. Restent la langue et les préoccupations de l'un des plus grands écrivains du XX siècle. 